\title{
LA SERPIENTE DE AGUA EN LA COSMOVISIÓN Y RITUALIDAD DE LOS NGIGUAS DE SAN MARCOS TLACOYALCO, PUEBLA, MÉXICO
}

\author{
Alejandra GÁMEZ ESPINOSA \\ Benemérita Universidad Autónoma de Puebla (México) \\ agamez_09@yahoo.com.mx
}

\begin{abstract}
WATER SNAKE IN THE WORLDVIEW AND RITUALISM OF NGIGUAS OF SAN MARCOS TLACOYALCO, PUEBLA, MEXICO
\end{abstract}

Resumen: La cosmovisión y la ritualidad mesoamericana han tenido como fundamento centralla naturaleza, debido a que las sociedades indígenas históricamente han basado su subsistencia en la agricultura, lo que las ha hecho altamente dependientes de los fenómenos naturales como la lluvia y la fertilidad de la tierra, de las cuales depende el crecimiento del maíz. Por ello muchas de las antiguas deidades mesoamericanas relacionadas con el agua siguen siendo símbolos dominantes en la cosmovisión de gran parte de los pueblos indígenas de México. Los fenómenos naturales han sido concebidos como sujetos humanizados con voluntad propia, con los cuales se mantienen relaciones de dependencia, reciprocidad y poder tal es el caso de la denominada Gran Víbora de Agua. El objetivo de este texto es proporcionar un análisis etnográfico de las actuales configuraciones de la cosmovisión y la ritualidad indígena entre los ngiguás o popolocas del sureste de Puebla (México), a partir de la descripción de un ritual propiciatorio dedicado a una deidad dadora de lluvia, llamada también la Serpiente emplumada. Consideramos que el ritual es uno de los dispositivos privilegiados para la trasmisión y reproducción de la cosmovisión.

Abstract: The Mesoamerican cosmovision and rituality have had their main argument in nature, because of native societies have historically based their subsistence in agriculture, which have made them highly dependent in natural phenomena like rain and soil fertility in which the growth of corn depends. That is why many of the ancient Mesoamerican deities related to water remain as dominant symbols in the cosmovision of great part of Mexico's native people. Natural phenomena have been conceived as humanized self-will subjects, with which remains relations of dependence, reciprocity, and power, such is the case of the so called "Gran Vibora de Agua". The objective of this paper is to provide an ethnographic analysis of the current configurations of the cosmovision and indigenous rituality among the "nguguas" or the "political" in the southeast part of Puebla (Mexico), starting from the description of a propitiatory ritual dedicated to a rain-giver God, also called "Serpiente Emplumada". We consider that the ritual is one of the privileged devices for transmission and reproduction of the cosmovision.

Palabras clave: Cosmovisión. Ritual. Agricultura. Reciprocidad. Indígena Cosmovision. Ritual. Agricultura. Reciprocity. Native people 


\section{Introducción}

En la cosmovisión y la ritualidad de los grupos indígenas del sureste del estado de Puebla coexisten una serie de creencias sobre entidades de naturaleza que controlan el clima junto con el culto a los santos, tal es el caso de los llamados dueños de los cerros, los rayos, los aires y específicamente una gran Víbora emplumada o Víbora de agua. En la comunidad popoloca y/o ngigua de San Marcos Tlacoyalco (Municipio de Tlacotepec de Juárez en el estado de Puebla), se cree principalmente en la existencia de esta última entidad, la cual habita en la cueva de un cerro y se le atribuyen propiedades de control del clima como atraer lluvias para los campos de cultivo y grandes tempestades, por ello en determinadas épocas del año, o cuando así se requiere, los especialistas de la comunidad acuden a la cueva-cerro a hablar con ella para pedirle lluvia, está solicitud se realiza a través de un complejo ritual constituido por varias fases, así también los especialistas tienen que atender una serie de prescripciones dictadas por la costumbre. Este ritual, se lleva a cabo de manera clandestina y solo en periodos de atraso de las lluvias o sequias. Todo este conjunto de creencias, prácticas y relaciones sociales, que los ngiguas mantienen con esta entidad corresponden a configuraciones religiosas singulares, las cuales se caracterizan principalmente por la reproducción de creencias en torno a ciertas entidades de la naturaleza, mismas han subsistido de forma paralela al proceso de sincrestismo iniciado desde la Colonia española (Bartolomé, 2005, p. 5).

Actualmente es reconocido el hecho de que las comunidades indígenas, históricamente, mantuvieron una relativa autonomía religiosa respecto de la Iglesia Católica, el control eclesiástico no se pudo ejercer de forma estricta sobre todos los ámbitos, situación que determinó el desarrollo de una orientación local y comunitaria en el proceso de reestructuración religiosa. Las religiones que practican los pueblos indígenas, por tanto, responden a procesos históricos distintos, es decir, que mientras en unos casos recibieron más influencia misional en otros escaparon al control directo del clero, las respuestas simbólicas y sociales fueron distintas según las condiciones históricas específicas. Es por ello que hoy encontramos una gran complejidad de expresiones religiosas indígenas.

Uno de los aspectos de dicha complejidad es que en ella confluyen tanto componentes que le dan unidad como diferenciación. Es decir, que todas las comunidades indígenas forman parte de la tradición cultural mesoamericana y, por otra parte, recibieron y continúan siendo receptoras de la imposición del catolicismo desde la época colonial hasta nuestros días. Este proceso constituye un factor de homogeneización en el sentido de que ambas tradiciones están presentes en todas las culturas indias. Sin embargo, los estudios etnográficos en México dan cuenta a la vez de la rica diversidad de prácticas y creencias existentes en las comunidades, a razón de que cada una ha vivido su propio proceso de incorporación, apropiación, interpretación y resignificación de esos rasgos (Bartolomé, 2005, p. 4).

En cada comunidad se observa una especial configuración ${ }^{1}$ de elementos que pueden ser compartidos, pero que adoptan un papel singular, específico, dentro del contexto al cual pertenecen. Es por ello que hablar de un sincretismo generalizado al interior de la religión indígena puede contribuir a confusiones, ya que todas las comunidades realizaron sus propias traducciones, reinterpretaciones simbólicas dando lugar a lo que Bartolomé (1990, p. 42-43) denomina configuraciones, cada una de las cuales se encuentra íntimamente relacionada con las matrices ideológicas preexistentes.

Las religiones indígenas responden a configuraciones nuevas que, en muchos casos se encuentran distanciadas de las tradiciones que les dieron origen, remplazadas por una cos-

1 Entendida como "combinaciones singulares de rasgos compartidos que se constituyen como totalidades diferenciadas". Las distintas configuraciones son resultado de los procesos y contextos históricos y culturales a los que han estado sujetas cada una de las comunidades (Bartolomé, 2005, p. 6). 
movisión cuya estructura ordenadora alude pero no reproduce en forma lineal a las tradiciones que le dieron origen (Bartolomé 2005, p.43).

La religión indígena es un sistema de creencias, prácticas e instituciones que se caracterizan por carecer de teólogos al estilo de las religiones históricas, existen especialistas rituales como los tiemperos, curanderos, etcétera, que son en un momento dado quienes sistematizan, transmiten y legitiman las creencias, las cuales nunca fueron escritas, tampoco sus doctrinas y reglas, a ellas se accede a través de las narraciones orales (mitos, narraciones, cuentos, etc. frecuentemente desacralizadas) y de la observación de las prácticas rituales a las que están dedicadas. Por ello son religiones que nunca adquirieron carácter de "oficiales", permanecen a través de la tradición oral. Las normas, comportamientos y reglas son trasmitidos oralmente de padres a hijos y de generación en generación.

Al respecto adquiere relevancia el ritual de petición de lluvia y "limpia del cerro" que se lleva a cabo en la localidad de San Marcos Tlacoyalco de manera esporádica, principalmente a finales del mes de abril y el cual está dirigido a entablar una relación con una gran Víbora que habita en las profundidades del cerro. Consideramos que las creencias en torno a esta entidad forman parte de un constructo complejo y holístico al que denominamos cosmovisión. Esta última que se construye a partir de las actividades vitales de la existencia humana y se expresa en un conjunto de actos y prácticas sociales como lo son los rituales. A través del análisis de la cosmovisión y la ritualidad en torno a la Víbora de agua buscamos contribuir a la comprensión antropológica de la visión de mundo contemporánea de los grupos étnicos del sur de Puebla, y explicar sus actuales configuraciones. Así mismo pretendemos aportar conocimiento sobre la cultura de los ngiguas en lo general y en lo particular sobre etnografía del ritual agrícola en los grupos indígenas de México.

La metodología utilizada para obtener las evidencias etnográficas fue el trabajo de campo, que consistió en estancias prolongadas en la localidad de San Marcos Tlacoyalco, donde si bien hicimos uso de la observación participante, principalmente realizamos entrevistas etnográficas a especialistas y actores que han participado en el ritual de petición de lluvia a la gran Víbora. No nos fue posible presenciar el ritual debido a que, según las creencias locales, a las mujeres no nos está permitido participar, por otro lado, la petición actualmente se realiza de manera clandestina y circunstancial.

La estructura del presente trabajo consta de tres apartados, en el primero enmarcamos teóricamente la investigación a partir de dos conceptos: cosmovisión y ritual, el segundo apartado versa sobre la cosmovisión en torno a la Víbora, su relación con la fertilidad y el agua entre los ngiguas, analizando comparativamente estos datos con otras partes de Mesoamérica, en la tercera parte se describe el ritual de petición de agua a la gran Víbora que se realiza en San Marcos Tlacoyalco, este último apartado a su vez se divide en tres segmentos donde se describe a los especialistas o "brujitos" encargados de realizar el pedimento a la entidad y en los dos restantes se describe propiamente el ritual el cual dividimos en dos grandes actos a los que denominamos: a) El encuentro: la consulta a la entidad por parte del especialista y b) El pedimento de lluvia en el cerro: el intercambio con la Víbora. Le dedicamos una especial atención a la descripción del ritual porque consideramos que este es uno de los dispositivos privilegiados donde se expresa de manera concreta la cosmovisión de un pueblo, a través del ritual también podemos analizar cómo se relacionan las personas con las entidades de la naturaleza, los valores y normativas que regulan estas relaciones, tal es el caso de la reciprocidad entre los ngiguas y la gran Víbora dadora de agua.

\section{La cosmovisión y el ritual}

El concepto de cosmovisión ha sido central en la antropología gracias a éste podemos acércanos a comprender una cultura diferente y analizar fenómenos sociales producto de otras formas "de concebir al mundo". Todo grupo humano posee una forma de ver, de 
pensar su entorno, de explicarse cómo se originaron las cosas, los seres vivos, los astros, la tierra, entre otros elementos; cómo funcionan, se comportan, persisten, desaparecen y se relacionan unos con otros.

Generalmente dentro la antropología el concepto más utilizado para hacer alusión a las formas mentales con las cuales los pueblos idean, representan y reflexionan su mundo es el de cosmovisión. Este concepto se encuentra estrechamente ligado con las creencias, percepciones, representaciones sociales, ideas, significados pensamientos y explicaciones sobre el mundo y el universo.

La cosmovisión es una expresión cultural, y la cultura es lo que diferencia a las sociedades; dota de sentido a la vida; hace pertenecer; genera formas de vida propias, únicas; hace existir a una colectividad; cohesiona a sus actores y legitima o deslegitima sus acciones. La cultura siempre es subjetiva y objetivada. Es decir, se distingue en dos formas, la interior y la exterior. La primera se refiere a las formas simbólicas y estructuras mentales como las ideas, representaciones, visiones del mundo, etcétera; y la segunda, a los símbolos objetivados en forma de objetos cotidianos, rituales, artísticos, etcétera (Giménez, 2007 p. 44).

De acuerdo con lo anterior, la cosmovisión es una forma de cultura interiorizada, constituida principalmente por representaciones socialmente compartidas. Estas últimas son sistemas cognitivos contextualizados que responden a una doble lógica: cognitiva y social (Giménez, 2007 p. 47). Las construcciones de la cosmovisión están relacionadas, sobre todo, con las formas mentales con las que una colectividad percibe, idea, representa y explica el universo, la naturaleza y al ser humano en sus mutuas interrelaciones.

La cosmovisión se construye y reconstruye en la vida cotidiana, en las prácticas rituales y en todo el hacer humano, es decir, surge a partir de las actividades vitales de la experiencia humana y se inscribe en un espacio y en un tiempo determinados, por tanto, está sometida a las variables de la historia y la cultura. Es una guía orientadora que coadyuva a la reproducción de la vida social y la regula, involucra las formas de relación y de comportamiento de los seres humanos, las entidades, las cosas, la naturaleza y el universo. La cosmovisión, entonces, plantea la instauración de un orden de la naturaleza, de la sociedad y del cosmos; esto perpetúa la legitimidad de ese orden; por tanto, es una construcción coherente y holística. Asimismo, posee una función identificadora que permite la construcción de identidades sociales y provee una guía para explicar el curso de los acontecimientos y legitimar los comportamientos pero, sobre todo, constituye un esquema de percepción por medio del cual los actores comprenden y explican su realidad.

Cada sociedad tiene miradas específicas en torno a su realidad, formas de ordenar su vida social y acciones para relacionarse con su medio, por tanto la cosmovisión es una construcción cultural, coherente y holística.

Los medios privilegiados de trasmisión y reproducción de la cosmovisión son los mitos y los rituales, por ello se han convertido en los dispositivos fundamentales para analizar la visión del mundo de un grupo humano. Dentro de éstos, los rituales han tenido una especial atención en los estudios antropológicos ya que son actos sociales que fundamentalmente expresan una forma de pensar y de concebir al mundo, es decir, una cosmovisión por tanto no podemos entender uno sin el otro, ya que forman una dualidad indisoluble. No hay sociedad sin una cosmovisión, es decir sin una construcción en donde se platee la existencia de un mundo otro habitado por deidades, donde la vida trascurre en plenitud y abundancia, y es el ritual la puerta de entrada entre el mundo real y el especial (Da Mata 2000, p. 55). A través del ritual los humanos entablan las relaciones más directas y duraderas con las deidades.

Los rituales son actos cuya característica es su ubicuidad, es a decir de Rappaport (2016, p. 54), un acto social básico para la humanidad y el escenario donde se crea y recrea la religión. Generalmente los rituales son actos de secuencias más o menos invariables y codificadas, formales, repetitivas, estereotipadas, que se ejecutan en tiempos y espacios previamente pactados y reglamentados y qué expresan cierto tipo de creencias y significados. 
Al ritual lo concebimos "como acciones pensadas y pensamientos actuados". La capacidad de fusión del ritual entre "pensamiento y acción" no implica cualquier pensamiento ni cualquier acción. El ritual representa una de las partes más importantes de la religión. Y éste representa un sistema de creencias que como un todo, se integran en el pensamiento - aquél que ha erigido una teoría del mundo (cosmovisión) - y los comportamientos (Díaz Cruz, 1996, p. 18).

Uno de los aspectos más importantes del análisis del ritual reside en que éste condensa múltiples aspectos de la cultura y la vida social de un grupo, incide en la reproducción de la sociedad, en la construcción y reproducción de la identidad colectiva (Broda, 2001, p. 166).

Siguiendo a Broda (2003, p. 16) consideramos que en el caso de las sociedades agrícolas de tradición mesoamericana, hay una combinación coherente entre las nociones sobre el medio ambiente y el cosmos en que se sitúa la vida del hombre. La práctica milenaria de la agricultura de maíz entre las culturas indígenas ha permitido la reproducción de una cosmovisión inspirada en ella y, los fenómenos relacionados con ésta, como el conocimiento del medio ambiente, el crecimiento del maíz, la fertilidad de la tierra, la preocupación por controlar el clima, atraer la lluvia, etcétera, todo ello motivó el desarrollo de una visión del mundo habitada por deidades relacionadas con los fenómenos naturales, así como la existencia de prácticas y ritos a través de los cuales se buscaba controlar el clima y mantener relaciones de reciprocidad para con las divinidades.

Los ngiguas, grupo indígena del sur de Puebla, históricamente han basado su subsistencia en la agricultura de maíz, razón por la cual en su visión del mundo figuran como elementos centrales, el agua, la tierra, el maíz, los cerros, la lluvia, los jagüeyes, los aires, las plantas y los animales, muchos de estos aspectos de la naturaleza han sido humanizados y cargados de poderes, voluntad propia y otras cualidades, tal es el caso de las víboras las cuales históricamente en la cosmovisión mesoamericana han estado relacionadas con el propiciamiento del agua, elemento fundamental para la fertilidad de la tierra y la vida de los giguas. $^{2}$

Desde el inicio de la civilización mesoamericana la serpiente ha sido un animal ampliamente representado en relación con la tierra, el agua y los poderes fecundadores, sin embargo ha sido difícil establecer la época en que comenzó a acumular significados tan versátiles como ninguna otra divinidad.

Actualmente la víbora sigue tenido un lugar preponderante en la cosmovisión de gran parte de las culturas indígenas del país. Los ngiguas la denominan "tecuancoa" y generalmente la asocian con el agua y la fertilidad, son considerados seres buenos porque se cree que cuidan a los humanos y protegen las milpas, ellas atraen la lluvia, cuidan los manantiales y tienen la propiedad de hablar con las personas.

\section{La tecuancoa. Cosmovisión en torno la serpiente y el agua entre los ngiguas}

Los ngiguas de San Marcos relatan que en el cerro La Flor -elevación perteneciente a la Sierra de Soltepec- habita una gran serpiente de colores muy brillantes que habla con los seres humanos; vive en una cueva donde permanece la mayor parte del tiempo. Suele aparecer generalmente en la época de lluvia, se pasea por las barrancas -aunque también se le puede ver en el resto del año- y cuando se enoja, sale de su cueva; las nubes se ponen negras y adquieren su forma, llueve mucho y provoca grandes trombas e inundaciones.

La serpiente tiene diferentes fisonomías: es grande, de muchos colores "muy bonitos", tiene plumas y a veces es alada. Es común que sea la figura que representa al dueño del agua o del cerro. En algunos pueblos de Oaxaca la Gran Serpiente o culebra es la protectora y

2 Ngigua es el término con que se autodenominan actualmente los popolocas, en oposición al vocablo "popoloca" que fue impuesto por los mexicas y que tiene una connotación despectiva. En el presente artículo utilizamos el apelativo local ngigua de San Marcos Tlacoyalco. 
guardiana de los manantiales, a la cual se les ofrecen velas y una ofrenda para que les deje acercarse (Barabas, 2003, p.83), (cf. Broda, 1991, pp. 467-473). Esta misma visión en torno a la víbora está presente en muchos pueblos del sureste de Puebla, en los manantiales es frecuente que habiten víboras "de agua" las cuales son respetadas y protegidas por las comunidades ya que se cree cuidan, resguardan y garantizan que los nacimientos generen agua.

En la cosmovisión ngigua, el cerro donde habita la gran serpiente es el lugar donde se guarda el agua y el maíz de la comunidad, es considerado "la troje del pueblo" y esta entidad vive y custodia la cueva de acceso a las profundidades de la "troje", por ello para entrar se requiere de su permiso, así como conocer el camino, de lo contrario la persona se pierde y nunca sale. A los individuos que saben de la localización de la cueva y la forma de dirigirse a la víbora, los llaman brujos. Se cree que cuando caen grandes trombas esta entidad baja por los caudales de agua que descienden por las barrancas, muchos pobladores la han visto y dicen que es gigante y tiene plumas. ${ }^{3}$ Por ello cuando baja a las planicies puede volver a subir, ya que con sus plumas vuela.

Para tener la protección y obtener los favores de la serpiente, los ngiguas de San Marcos realizan un ritual de pedimento de lluvia (otros le llaman de "limpiar la cueva") para los campos y le llevan ofrendas, pero le solicitan determinada cantidad de agua; "porque ésta no debe ser en abundancia porque inunda los campos de cultivo y pudre las plantitas". A la gran Víbora le agrada que le lleven lo que pide (flores, comida y ceras), así como que sean personas jóvenes ${ }^{4}$ los que coloquen su ofrenda.

Hoy algunas personas dicen que ya no piden lluvia en el cerro, que ya no "platican con una víbora grande", porque esa "práctica ya no se ve bien". El sacerdote les ha dicho que es "malo" y que no es correcto que realicen esas ceremonias en el cerro. Otras personas piensan que quien ve una víbora muy grande puede estar en peligro de ver "al mal y perder su alma", ya que este no es concebido como un animal, sino como una representación del "mal", hay quien asegura que esa víbora es Chinentle, sin embargo la gran mayoría dicen que ésta no es mala, no hace daño y los protege.

Chinentle es una entidad, un dueño, que habita en el cerro. En lengua popoloca se le denomina también Chi-yí o Chijía-a que significa, de acuerdo con los hablantes actuales "diablo o el malo", también es conocido como Chanentle y se dice que sus seguidores eran los Chantile (los antepasados), quienes eran personas que no estaban bautizadas en el nombre de Dios, consideradas "personas naturales".

Actualmente muchas de las antiguas deidades mesoamericanas siguen siendo ejes dominantes en la cosmovisión de gran parte de los pueblos indígenas del país. Los seres y fenómenos naturales milenariamente han sido concebidos como sujetos humanizados con voluntad propia, con los cuales se mantienen relaciones sociales de dependencia, recipro-

3 La presencia de la gran serpiente con plumas es una entidad central en las cosmovisiones indígenas de México. Se sabe que en el periodo Clásico aparece con sus rasgos de serpiente cubierta de plumas preciosas en las pinturas murales de Teotihuacán ( $C f r$. Florescano, 1993). La serpiente posee un profundo simbolismo agrícola y es el más antiguo y también el que más permanece en la cosmovisión de los pueblos campesinos contemporáneos, quienes creen en la existencia de una entidad en forma de serpiente emplumada que vive en la profundidad de las cuevas y barrancas de sus poblados. Este ser es también quien otorga los mantenimientos y tiene un aspecto celeste, ya que cuando surca los cielos viaja sobre las nubes generadoras de las lluvias para germinar las plantas. En la cosmovisión mesoamericana, la serpiente emplumada se relaciona con el ciclo de crecimiento del maíz, cuyas hojas verdes se comparan con las plumas del quetzal; las mazorcas se confundían con las escamas de su cuerpo. Durante la época de lluvias, los campos agrícolas con las plantas de maíz y sus hojas verdes en movimiento se expresan mediante la metáfora visual de que la serpiente emplumada como una gran monstruo cubre toda la extensión de las parcelas (Castellón, 2002, pp. 29-30).

4 Generalmente se hace alusión a que la gran víbora siempre solicita que las personas que acompañen al curandero en la entrega y colocación de la ofrenda sean jóvenes. Creencias que son similares a la cosmovisión y prácticas rituales prehispánicas, en torno a los gustos del dios Tlaloc al cual se le sacrificaban niños. 
cidad y poder. Éstos reciben diversas connotaciones como: dueños de lugar, rey, caballero, patrones, dueño del cerro, señor, etcétera. Los dueños de lugar o de los montes son entidades multisignificativas y ambivalentes, un Dueño se puede desdoblar para cumplir diversas tareas y puede ser una entidad que represente a la tierra, al agua, al maíz, a los antepasados, o pueden ser los fundadores de los pueblos, entre otras. Son ambivalentes porque pueden ser caprichosos y exigentes pero también, dadores y protectores. En las comunidades ngiguas manifiestan que unos son "buenos" y otros "malos". Su dominio característico son los cerros o montes y son concebidos como personas poderosas que a veces vive en los pueblos, son entidades territoriales que delimitan lugares, los protegen, moran en ellos, en muchos casos son los lugares mismos.

Los dueños pueden ser hombres y/o mujeres. Cuando se trata de la deidad del agua o el dueño del agua, su morada es principalmente el cerro, pero también puede ser el manantial, el jagüey, la cueva y la laguna, entre otros sitios. La divinidad del agua se manifiesta de diversas maneras como puede ser en nahual, serpiente o culebra (Barabas, 2003, p. 58). Entre los ngiguas de Tlacoyalco la Víbora emplumada es una de las manifestaciones de Chinentle, sin embargo, esta representación no tiene connotaciones negativas como es el caso de otras relacionadas con la riqueza mal habida. Se considera fundamentalmente "riqueza mal habida" aquella que se obtiene a través de un pedimento individual en el que "se vende el alma de la persona" a cambio de fortuna. Generalmente los dones entregados a una sola persona y/o familia, que presentan la acumulación de riqueza individual, es vista de manera negativa y sancionada en la cosmovisión comunal -ya que trasgreden el orden social- y se contrapone a las prácticas y dones que buscan el beneficio y bien colectivo, las cuales son vistas positivamente.

La imagen del mal relacionada con el diablo fue incorporada a numerosas características de las divinidades mesoamericanas principalmente vinculadas a la obscuridad y el inframundo durante la época de la Colonia (Barabas, 2003, p.63). La ambivalencia de los dioses mesoamericanos dificultó su compresión y los europeos, bajo la visión cristiana del mal, los relacionaron con demonio. Bajo esta óptica no pudieron percibir que se trataba de deidades que actuaban entre lo sagrado y lo profano, entre la vida y la muerte, entre la bondad y maldad y que dan pero también quitan; otorgan fertilidad y agua pero igualmente provocan tempestades y castigan (Barabas, 2003, p.51). En este contexto la noción de diablo fue reelaborada por los pueblos indios.

Este proceso fue desarrollándose progresivamente a medida que los pueblos evangelizados fueron destacando el carácter negativo de aquellos signos y símbolos relacionados con las prácticas religiosas antiguas, las cuales pasaron a integrar un sustrato ideológico y valorativo vivido no como peligroso pero sí ambivalente en donde se conciben a las deidades como seres "malos" malignos o diabólicos, frente a los seres católicos entendidos como "buenos" (Barabas, 2003, p.19).

Actualmente Chinentle es una entidad ambivalente que según lo que represente puede ser considerado "bueno" o "malo", si adquiere la forma de Víbora emplumada dadora de agua para beneficio de la colectividad es bien vista, pero si por lo contrario, toma la forma de un charro negro y/o un hacendado que intercambia riqueza individual a cambio del alma humana es percibido como maléfico, es decir como el diablo.

Chinentle como entidad del agua se manifiesta en la gran Víbora que también puede asumir la apariencia de una tecuancoa, serpiente de enormes proporciones, descrita como: "un animalón muy grande y gordo". Es común que se les aparezca a las personas, pero no les hace daño. Algunos habitantes de Tlacoyalco expresan que generalmente se deja ver para indicar donde hay dinero: "en el agujero dónde se mete es señal de que ahí hay dinero", en estos orificios se dice que se puede encontrar oro y monedas grandes que se pueden vender en Tehuacán, pero la víbora no pide a cambio el alma de la persona.

En otras comunidades ngiguas como San Juan Atzingo, localizada al sur valle de Te- 
huacán, la percepción de la víbora es compleja y está relacionada con el buen desarrollo de la milpa, es llamada localmente como "masacoa" y la describen como similar a la víbora de cascabel pero más gruesa y grande, de colores obscuros casi negros. Ésta se caracteriza por tener la imagen de una cruz en su frente, es considerada como un "animal bueno" que cuida los campos de cultivo, se alimentan de los insectos y demás depredadores que dañan la milpa y roban la mazorca (como la rata de campo y el conejo), también cuidan a los seres humanos y entre otras de sus muchas cualidades, está el hablar con las personas, de acuerdo con los pobladores cuando una víbora se encuentra en peligro, éstos se encargan de prevenirlas, de esa manera ambos se protegen.

Actualmente en la región del valle de Tehuacán donde se ubica San Marcos Tlacoyalco, ya no llueve con la intensidad de antes, al respectos algunas personas explican que es porque en la década de los setentas, pasó por el lugar un cometa que se llevó a la Víbora de agua, algunos aseguran que vieron cómo pasó la estrella y detrás de ella iba la Víbora con su gran plumaje y la vieron alejarse hasta que desapareció, esto provocó que ya no lloviera como en antaño y que los campos ya no den alimentos suficientes para el pueblo, especialmente que el "maicito ya no crezca ni dé grandes mazorcas".

Otros expresan haber visto cómo un remolino de aire provocó que las nubes se enrollaran y tomaran la forma de una Víbora; desde ese tiempo se observa "cómo viene la lluvia, pero aparece un aire fuerte del sur y se la lleva". Sin embargo, en la mayoría de los casos aseguran que la gran Víbora, cuando está molesta por que no la ofrendan, provoca grandes tempestades y baja por los caudales de agua que corren por las barrancas, trayendo consigo inundaciones y llevándose todo lo que encuentra en su camino, como casas y ganado. La Víbora viaja hasta el mar y como tiene alas regresa al interior del cerro, en este sentido las "serpientes emplumadas" representan el vínculo existente entre la lluvia y el mar, ya que es en este último donde la humedad permite la creación de las nubes que generan la lluvia.

\section{El ritual: la petición de agua a la gran Víbora}

Los rituales son actos sociales que responden a la visión del mundo de los grupos humanos, éstos se realizan en lugares y en tiempos previamente pactados y reglamentados por la costumbre, generalmente están conformados por una serie de secuencias que van desde los preparativos, el clímax y su conclusión, Van Gennep (Van Gennep, 1986, p. 25) por ejemplo, habla de tres fases constitutivas del ritual al que denominó de paso: la separación, la transición (liminal) y la incorporación (posliminal). Los rituales generalmente reúnen una serie de acciones sociales que se desplazan en un espacio (lugares sagrados) y un tiempo específico, todo ello mediado por la costumbre. El ritual de petición de lluvia en San Marcos Tlacoyalco está conformado por dos actos rituales fundamentales. El primero es un ritual preparatorio al que denominamos el encuentro (acto donde el especialista consulta a la entidad sobre el tipo de intercambios de dones -la ofrenda- que requiere para conceder la lluvia, así como también pactan la fecha en que se consuma el intercambio y la petición); y el segundo, donde se consuma el objetivo del ritual, el pedimento de lluvia, se trata del acto en donde se realiza propiamente la solicitud y se entrega la ofrenda a la entidad.

Dentro de la vida religiosa y social de las comunidades ngiguas, el ciclo ritual agrícola es el de más relevancia debido a que la economía indígena, pese a la crisis del campo en el sur de Puebla, sigue basando en buena medida su subsistencia en la agricultura. Los rituales agrícolas son aquellos que buscan favorecer el buen desarrollo de la agricultura fundamentalmente de maíz, a través de la obtención de agua, fertilidad de la tierra, control del tiempo para asegurar el crecimiento de las plantas (alejamiento del granizo, heladas, plagas, tormentas de agua mala etc.), protección (bendición de las semillas) y buena cosecha (pedimento y agradecimiento a las deidades). Éstos en general son rituales que podían entrar en la categoría de los denominados propiciatorios (Barabas, 2006, p.20). 
Los rituales propiciatorios son acciones que buscan obtener algo como salud, suerte, desempeño como autoridad, trabajo, conocimiento para sanar, buen camino en la migración, protección, dinero, bienes materiales, ganado y aspectos para el buen desarrollo de la agricultura como agua, fertilidad, cosecha y alejamiento de heladas, granizo y plagas. Consisten en actos donde se pide, ruega, implora etc. a las entidades que otorguen lo solicitado. Éstos pueden ser actos sumamente elaborados que involucran a gran cantidad de personas (procesiones, ofrendas, danzas, convites, sacrificios etc.), así como también sencillos actos rogativos mediados por una ofrenda.

En la comunidad de estudio, días antes de la fiesta dedicada al patrono, san Marcos Evangelista, el 25 de abril, se realizan rituales de petición de lluvia o agua en el "Cerro de la Flor", en popoloca se le nombra como Icha duo o Naxradué, éste se encuentra al norte del pueblo, al pie del monte grande conocido como La Cuesta, en este lugar existe una cueva estrecha donde en su interior habita una gran Víbora. Aquí cada año se introducen los encargados de la comunidad para "pedir agua". Algunas personas refieren que era en el cerro Tepoztla (cerro del peñasco grande) donde antiguamente se realizaba la petición. Los indicados para pedir agua en la serranía son conocidos como "gente del cerro", se dice que hace una década ellos iban a un lugar muy peligroso en lo alto del monte donde abundaban víboras, lagartijas y tarántulas. Para el buen desarrollo de su travesía llevaban consigo blanquillos de color blanco, los cuales servían como prenda para que las víboras no los lastimaran y los dejaran pasar a las profundidades de una caverna donde pedían agua para el pueblo, en su interior había mucha humedad, se filtraba agua, existía abundante agua acumulada, se escuchaba el sonido de un fuerte viento y truenos. En el fondo donde concluía la cavidad, hacía su aparición una gran Víbora de agua la cual era emplumada, otras versiones mencionan que se encontraba una escultura de piedra de forma humana:

.....en la cueva del cerrito de la Flor, no hay cruz, cuentan los abuelitos, que había un muñeco de piedra, dicen que es como un bulto o un costal grande que tiene la forma de un muñeco, con cabeza, manos y pies, dicen que la piedra con que está hecho es obscura, no sé si estaba sentado o de pie (señor Martín, San Marcos Tlacoyalco, 2014).

Otras narrativas señalan que se trata de una cruz de madera, la cual representa a la Víbora, frente a la cual los curanderos rezaban y pedían agua. Generalmente la petición de lluvia se realizaba a finales del mes de marzo o abril, sin embargo cuando las lluvias se retrasaban o escaseaba el agua, se ejecutaba nuevamente el ritual, se dice que subían a la cueva dos o tres veces en la temporada de lluvias y en algunas ocasiones con una sola vez era suficiente.

\section{Los especialistas}

Las personas que realizan el ritual de petición de agua son conocidas como curanderos o "brujos", anteriormente se les nombraba "gente de conocimiento" o "conocedores". En San Marcos había varios varones mayores de 40 años que eran reconocidos por su conocimiento para pedir la lluvia, muchos de ellos se decía eran certeros, sin embargo, sólo se nombraba a uno de ellos para hacer la tarea, por eso se dice que existía mucha competencia entre los llamados brujitos, "para demostrar quién era el mejor".

Los brujos o conocedores son considerados seres humanos especiales porque tienen conocimientos y "licencia" la cual fue otorgada por la divinidad, "no cualquiera puede llegar a ser un curandero", son personas fuertes, que no sufren de debilidad y no se enferman de "mal de aire", se dice que están "protegidos".

Para ser curandero se necesitan ciertas habilidades y conocimientos que son trasmitidos de generación en generación, son personas que saben y tienen el don (sabiduría, conocimiento por mandato divino) para hablar con la Víbora y conocen el lugar donde se localiza la cueva "donde se pide el agua", sólo se introducen los que tienen "licencia" (don), de lo contrario las personas que intentan adentrarse pueden perderse y morir. Las mujeres por 
ejemplo, se les considera seres "débiles", que "no tienen el permiso para entrar ni ver la cueva", su participación directa en este acto ritual está prohibido, su ingreso a la caverna podría desencadenar una enfermedad y/o la muerte.

Los curanderos encargados de "pedir agua" se eligen entre los habitantes del pueblo y son enseñados por los que saben, uno de los atributos que se señalan como indispensables para ser elegido curandero es la fortaleza espiritual y física.

Anteriormente quien elegía al especialista encargado del ritual de pedimento, así como también a la comitiva que lo acompañaba, era el Presidente Auxiliar del pueblo. El grupo estaba constituido por cinco personas de sexo masculino, el resto de la población no sabía, ni sabe, dónde se encuentra la cueva y no participaba en el acto ritual de manera presencial. La manera en que el pueblo asumía su tarea y participación en beneficio del pedimento, era a través de la compra de los objetos (cestos, tenates, ceras, flores etc.) alimentos, bebidas etc. que constituían la ofrenda y en la realización de ciertas labores, las mujeres por ejemplo, eran las encargadas de preparar los alimentos y platillos que se le ofrecían a la Víbora. El acto ritual no tenía una fecha específica "no es un día fijo", éste podía variar y ser consensuado entre la entidad y el especialista, sin embargo, la fecha tenía que ser determinada en el mes de abril o a finales de marzo, días antes de la fiesta dedicada a san Marcos Evangelista. Este periodo es fundamental en la región ya que es cuando se espera la llegada de las primeras lluvias y con ello el inicio de la siembra de los campos de temporal.

\section{El encuentro: la consulta a la entidad por parte del especialista}

Días antes de la realización del ritual de petición de lluvia el Presidente Auxiliar de San Marcos Tlacoyalco nombraba al especialista o "brujito" que sería el encargado de ejecutar dicha tarea, así como a una comisión que se encontraba formada por un grupo de cinco o seis hombres, generalmente eran personas de confianza o amigos del especialista, "el brujito invitaba a sus amigos para que lo acompañaran", éstos tenían como tarea apoyarlo en la difícil labor de viajar a la cueva donde habitaba la Gran Víbora y consultarle sobre el tipo de alimentos que deseaba comer y que constituirían parte de la ofrenda en su honor, a cambio esta entidad concedería la lluvia al pueblo. De esta manera se generaba un intercambio entre los habitantes de San Marcos y la Víbora, ésta recibe alimentos a través de una ofrenda y los seres humanos a cambio reciben protección y dones como agua, fertilidad etc.

Las relaciones de los ngiguas de Tlacoyalco y las entidades sagradas generalmente están sustentadas en el intercambio, en la literatura antropológica a éste se le denomina el don. Este último no es sólo mecanismo de circulación de bienes y servicios, sino la condición misma de producción y reproducción de relaciones sociales que constituyen el tejido social y caracterizan los vínculos que se entablan entre las personas, los grupos humanos y las deidades. El don es un acto voluntario pero supone, implícitamente, la obligación de retribuir, es un compromiso ineludible, un pacto sancionable de manera moral (Barabas, 2006, p. 152). El intercambio, el don, es reciproco (dar, recibir y devolver) entre los seres humanos y entre éstos y las deidades, e implica la búsqueda del equilibrio tanto social como natural. La reciprocidad es una forma de control social apoyada en sanciones sociales y religiosas que prescribe la normatividad social (Barabas, 2006, p. 153).

Así el don es un ejercicio religioso que relaciona a los ngiguas con las deidades. Sin embargo, estas relaciones son de dependencia, porque las deidades son poderosas y creadoras de todo lo que existe, por tal razón la humanidad siempre está en deuda con ellas. Las personas solicitan, agradecen, ruegan, imploran, pero nunca exigen, ya que dependen de los actos y deseos de las divinidades (Godelier, 1998, p. 256).

Según diversas versiones la cueva donde habita la gran Víbora es muy larga y tiene muchas bifurcaciones, se dice que es como un gran túnel cuyo término llega hasta el cerro Colorado, lugar próximo a la ciudad de Tehuacán, lo que implica que el camino es compli- 
cado, peligroso, extenso y requiere mucho tiempo de esfuerzo para acceder al lugar donde se encuentra la entidad. Por tal razón la comisión encargada de consultar a la serpiente tenía que salir muy temprano rumbo al cerro de La Flor, llevando consigo todos los implementos que requerían para lograr su cometido, dentro de los más importantes estaban varios manojos de una planta a la que localmente llaman "cucharilla". Cuando el grupo llegaba a la entrada de la cueva, sólo el brujo podía adentrase a sus profundidades y pasar por un laberinto de bifurcaciones internas, la estrategia para no perderse era hacer un camino con trozos de cucharilla que iba dejando en el suelo y así poder encontrar el camino de regreso. El especialista sabía localizar en sitio donde se realizaría el encuentro entre él y la Gran Víbora, su conocimiento y experiencia lo guiaban así como una serie de señales: "se escuchaban truenos, se mecía la tierra como temblor, había ventarrones que apagaban las ceras que se prendían".

Cuando el brujo llegaba al sitio del encuentro, tenía que llamar a la Víbora e implorarle su presencia para iniciar una conversación en la que le solicitaba su auxilio al pueblo, la deidad por su parte le decía qué alimentos y objetos quería se le ofrendaran para conceder su amparo protector, que consistía en enviar lluvia para los campos. Al respecto se relata:

Le pedía que se presentará, que el pueblo de San Marcos necesitaba de su protección, eso se hablaba en el idioma, a veces llegaba rápido y otras veces no; la señal de que la víbora iba a su encuentro era que dentro del cerro, escuchaban truenos, se mecía la tierra como temblor.... El brujo tenía que aguantar de pie y no tener miedo; dicen que muchos salían corriendo y no aguantaban la situación. La Víbora ya conoce al brujo, hasta se hacían compadres; y hablaban entre ellos, se le pedía la lluvia para el pueblo, la víbora le decía que quería comida, pedía mole, carne de guajolote o chivo, tortillas, aguardiente; todo lo quería en trastes de barro nuevos. Entonces el brujo salía del cerro y venían de regreso al pueblo, le daban a conocer al presidente del pueblo que la víbora había pedido comida (Señor Mario, San Marcos Tlacoyalco, 2006).

El arribo al pueblo, de la comisión que acudía al encuentro con la Víbora, era esperado con gusto por todos los habitantes, quienes lanzaban cohetes para anunciar su regreso y se realizaba un convite en su honor.

\section{El pedimento de lluvia en el cerro: el intercambio con la Víbora}

Los encargados del pedimento subían muy temprano (durante la madrugada) a la cuevacerro, llevando consigo todos los utensilios y alimentos que necesitan para realizar el ritual, generalmente se trataba de hombres adultos fuertes que podían cargar cosas pesadas como canastos grandes y cazuelas con comida. Durante su trayecto a la cueva iban formando un camino con hojas de cucharilla o sotolín, como señal para encontrar el camino de regreso. Se dice que como prueba de que los curanderos realizaron su cometido, "traían una o varias piedras de color negro que tomaban del interior de la cueva".

Una vez que llegan al acceso de la caverna se introducía el curandero o "brujo" con uno o dos especialistas, sus acompañantes - la comisión- permanecían afuera esperando, únicamente las personas con "conocimiento" tenían la autorización de ingresar.

El interior de la caverna se describe como un laberinto, por lo que el especialista para no perderse y encontrar la salida de regreso, iba dejando una serie de marcas o señales. Una vez que llegaba frente a la Víbora de agua -que podía estar representada por una escultura de piedra y/o cruz de madera, según las diversas versiones-, enunciaba algunas oraciones en lengua ngigua y colocaba en el piso una ofrenda que consistía en comida (arroz, mole, 
tortillas), bebidas (refrescos, aguardiente y pulque), además de ceras, flores de varios colores y huevos. Todos los platos y objetos en donde se colocan los alimentos y demás cosas debían ser nuevos, de lo contrario se provocarían el enojo de la deidad. La constitución de los alimentos de la ofrenda podía variar debido a que, como se mencionó anteriormente, la gran Víbora se comunicaba con el curandero antes del ritual y le indica qué tipo de alimentos y objetos quería para conceder al pueblo el agua de lluvia. Parte del rito es narrado por un informante que presenció el acto en la década de los noventa:

Los platillos ofrendados como mole, carne de guajolote y tortillas eran cocinados por las mujeres del pueblo que daban su cooperación para la realización del ritual, otros proporcionaban maíz o chile o dinero para comprar flores, velas, etcétera. También se quema copal durante el acto, los trastes donde se colocan los alimentos tenían que ser nuevos y eran retirados del lugar, una vez que la Víbora estaba satisfecha, lo único que se dejaba eran las flores, huevos y las ceras, éstas últimas eran utilizadas para alumbrarse dentro de la cueva, y para proteger al brujo de no contraer "mal aire" del interior; se cree que el humo que expiden éstas ahuyenta el "mal aire" (don Juan, San Marcos Tlacoyalco, 2006).

La mayoría de los habitantes expresan que los huevos ofrendados tenían que ser de pavo y de color blanco. La presencia de este tipo de huevos tiene un simbolismo muy especial ya que se relaciona con el maíz, según los pobladores éstos debían ser muy grandes de preferencia de guajolota, ya que estos representan a la semilla de maíz blanco, que es el que se acostumbra a sembrar en la región.

En este acto ritual se le pedía a la gran Víbora, la cantidad de agua que necesitaba el pueblo para poder subsistir, por ejemplo se solicita un cuarto de agua, media manga o una manga completa, la cantidad la indicaba el Presidente Auxiliar de acuerdo al conocimiento que éste tenía sobre las tierras cultivadas. Una manga significa una tromba, media manga es lluvia intensa y un cuarto de manga son lluvias leves. Si la Víbora no enviaba el agua al pueblo, nuevamente se tomaba la determinación de realizar el ritual con el anhelo de que escuchara la súplica y recibiera la ofrenda que se le entregaba.

En años pasados cuando partía la comisión para realizar el pedimento de agua, se lanzaban cohetes que anunciaban su salida y regreso: "se daba a conocer que se había cumplido con esa promesa". Actualmente el acto ritual del pedimento de agua a la gran Víbora, se efectúa de manera clandestina y desarticulada del ciclo ritual agrario comunal. Sobre las personas que todavía realizan estas prácticas rituales se dice que no se sabe quiénes son y generalmente se evade hablar del tema.

El acto de colocar una ofrenda a las deidades de origen mesoamericano, se sincretizó con el culto a los santos católicos; actualmente al santo patrono del pueblo, san Marcos, también se le coloca una ofrenda en su altar el 25 de abril y el 7 de octubre. Algunas versiones sostienen que como muestra de que la gran Víbora otorga y crea el agua, existen en la cueva y en los cerros unos depósitos naturales de agua acumulada a los que llaman chentile.

\section{A manera de conclusión}

La diversidad religiosa, la evangelización católica y el proceso de globalización han conllevado a transformaciones en la cultura de los ngiguas. La costumbre de que el Presidente Auxiliar junto con algunas personas del pueblo, organizaran ciertos rituales como "el pedimento de agua", ocasionó conflictos internos debido a que estos cargos políticos, según las leyes del estado, podían ser ocupados por personas que profesaban otros credos religiosos lo que motivó que al no compartir las mismas creencias que el resto del pueblo, las criticasen y por lo tanto no se realizaran. Aunado a esta situación estuvo el hecho de que la Iglesia Católica y sus representantes, sancionaron y conminaron a los actores sociales a no realizar este tipo de prácticas por ser consideradas idolatras, malignas y penadas por Dios. 
Hoy la práctica ritual del "pedimento de agua a la Víbora", está desarticulada del ciclo anual comunal y sólo se realiza de manera clandestina a cargo de algunos curanderos o "brujitos", quienes lo mantienen en secreto debido a la censura de los sacerdotes católicos y miembros de otros grupos religiosos.

Actualmente muchas personas niegan que estos rituales se realicen, por temor a las sanciones, críticas y burlas de los sacerdotes católicos o de los miembros de las propuestas protestantes. Sin embargo, hay versiones encontradas: algunos argumentan que hay gente que todavía los practica pero que no saben quiénes son, otros dicen que ya no se efectúan por ser actos relacionados con el "mal", en contraste la mayoría sostiene que la Víbora emplumada no es "mala" y que cuando así se requiere se va a "limpiar la cueva" o a "pedirle agua a la Víbora" para que llueva.

A pesar de considerar a la petición de lluvia en el cerro, como relacionada con "el mal" los pobladores de San Marcos reconocen su efectividad y señalan que cuando se realizaban o realizan estos rituales sí llueve. Así la eficacia del ritual sigue siendo altamente reconocida, se trata de una acción comunitaria encaminada al dominio de lo inestable, por ejemplo el control del tiempo, que proporciona seguridad contra la angustia de la relación con lo sagrado, sobre todo cuando los santos "católicos" fallan ante sus hijos, los humanos.

La ética cultural comunitaria expresada en las formas de relación con las deidades a través de la reciprocidad, sigue siendo un mecanismo importante de cohesión social y reproducción cultural. Actualmente se comenta que ya no ofrendan a la gran Víbora o a Chinentle, sin embargo la costumbre de ofrendar se quedó y hoy lo hacen con los santos "católicos". Así mismo, en las fechas en las que veneraban y llevaban ofrendas a Chinentle, hoy celebran a su santo patrón, san Marcos, este último es visto como quien vino a salvar al pueblo de los compromisos que tenía con el "mal" (Chinentle). San Marcos adquirió algunos atributos de la antigua deidad del agua y actualmente, el pedimento de lluvia para los campos también se le hace a este santo "bueno", colocándole igualmente una ofrenda, sin embargo, en épocas de incertidumbre, cuando el santo no cumple, recurren nuevamente a las deidades del cerro. De esta manera ambos tipos rituales y de creencias conforman una singular religión: la religión indígena.

\section{Bibliografía}

Barabas, Alicia 2003. "Introducción: Una mirada etnográfica sobre los territorios simbólicos indígenas", en Alicia Barabas (coord.), Diálogos con el territorio. Simbolizaciones sobre el espacio en las culturas indígenas de México V. I, México, INAH (pp.15-36). México: INAH.

Barabas, Alicia 2006. Dones, dueños y santos. Ensayo sobre religiones en Oaxaca, México, INAH/. Porrúa.

Bartolomé, Miguel Alberto 2005. "Elogio del politeísmo. Las cosmovisiones indígenas de Oaxaca”, en Cuadernos de Etnología 3, Diario de Campo, INAH, CONACULTA, pp. 3-59.

Broda, Johanna 1991. "Cosmovisión y observación de la naturaleza: el ejemplo del culto a los cerros en Mesoamérica", en Johanna Broda, Stanislaw Iwaniszewski y Lucrecia Maupomé (eds.), Arqueoastronomía y etnoastronomía en Mesoamérica, México, UNAM, pp. 461500

Broda, Johanna 2001. "La etnografía de la fiesta de la Santa Cruz: una perspectiva histórica" en Johanna Broda y Félix Báez-Jorge (coords.), Cosmovisión, ritual e identidad de los pueblos indígenas de México, México, CONACULTA-FCE, pp. 165-238.

Broda, Johanna 2003. "La ritualidad mesoamericana y los procesos de sincretismo y reelaboración simbólica después de la conquista", en Graffylia Revista de la Facultad de Filosofía y Letras, Año I, num. 2, BUAP-FFyL, pp.16-30.

Broda, Johanna 2009. "Ofrendas mesoamericanas y el estudio de la ritualidad" en Johanna Broda y Alejandra Gámez (coords) Cosmovisión mesoamericana y ritualidad agrícola. Estudios interdisciplinarios y regionales, México, BUAP, pp. 45-66. 
Castellón Huerta y Blás Román 2002. "Cúmulo de símbolos. La serpiente emplumada” en Revista Antropología Mexicana, La serpiente emplumada, en Mesoamérica, vol. IX, num. 53, pp. 28-35.

Da Mata, Roberto 2002. Carnavales, malandros y héroes. Hacia una sociología del dilema Brasileño, México, FCE.

Díaz Cruz, Rodrigo 1996. "Horizontes rituales en Religión: el impacto social de la transformación de creencias y prácticas”, en Revista Iztapalapa Año 16, num. 39, México, UAM, pp. 15-23.

Florescano, Enrique 1993. El mito de Quetzalcóatl, México, FCE.

Giménez, Gilberto 2007. Estudios sobre la cultura y las identidades sociales, Colección Intersecciones, México, CONACULTA/ITESO.

Godelier, Maurice 1998. El enigma del Don, Barcelona, Paidos.

Heyden, Doris 1991. "La matriz de la tierra", en Johanna Broda, Stanislaw Iwaniszewski \& Lucrecia Maupomé (eds.) Arqueoastronomía y etnoastronomía en Mesoamérica, México, UNAM, pp. 501-525

López Austin, Alfredo 1984. Cuerpo humano e ideología. Concepciones de los antiguos nahuas, México: IIA-UNAM.

Manzanilla Lidia 2005. "La construcción del inframundo en el centro de México", en E. Vargas Pacheco (ed.) IV Coloquio Pedro Bosch Gimpera. El Occidente y el Centro de México, México, IIA-UNAM pp. 273-302.

Rappaport, Roy 2016. Ritual y religión en la formación de la humanidad, España, Ediciones Akal. Van Gennep, Arnold 1986. Los ritos de paso, Madrid, Taurus. 